\title{
Role of magnetic resonance imaging in the evaluation of the anterior knee pain
}

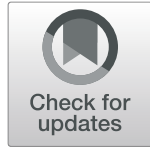

\author{
Ahmed Abd Alrahman Baz ${ }^{1 *}$, Khaled Mohamed El Shantely', Talaat Ahmed Hassan', Sherif Galal Mohamed ${ }^{2}$ and \\ Sara Ibrahim Sakr ${ }^{1}$
}

\begin{abstract}
Background: To review the most common causes of Anterior knee pain (AKP), with an emphasis on their MRI findings; 70 patients were included ( 24 males and 46 females). Their age range is $10-53$ years with a mean \pm SD of $28.8 \pm 9.06$ years. All patients performed MRI of the affected knee.

Results: Eleven disease entities were encompassed in this study; the patellar causes were dominating, where the chondromalacia patella being found in $43 \%$ of cases $(n=30)$, patellar instability was found in $19 \%(n=13)$, transient patellar dislocation was found in 7\% $(n=5)$, patellar tendinopathy was found in $4 \%(n=3)$, and bipartite patella was found in 1\% (n=1). Hoffa's disease was found in 14\% $(n=10)$; the anterior meniscal tear was found in 13\% $(n=9)$. Quadriceps tendinopathy was found in 3\% $(n=2)$, and quadriceps tear was found in $4 \%(n=3)$. Cartilage disease was found in $6 \%(n=4)$; Osgood-Schlatter disease was found in $4 \%(n=3)$; the coexistence of more than an entity was found in 13 cases (18.5\%).

Conclusions: MRI provided a safe and accurate modality in the diagnosis of different causes of AKP with a high specification in detecting the grades and the types of some diseases.
\end{abstract}

Keywords: Anterior, Knee pain, MRI

\section{Background}

The knee joint is a hinge joint and is considered as the most commonly injured joint in the body as it may be less stable than other joints of ball and socket pattern; however, the incidence of knee injury had been increasingly seen with the widespread interest in contact sports. Anterior knee pain (AKP) is by far considered the commonest cause of knee complaints, and it constitutes about $25 \%$ of all adult knee problems; nevertheless, it is commonly encountered in athletes and active subjects, especially the adolescents $[1,2]$.

AKP as a term may be interchangeably used with the term patellofemoral pain syndrome where the patella and the retinaculum constitute the main source of the complaints. It is considered as an incapacitating problem that has an impact on the subject lifestyle; however, its etiology is still not well understood making its treatment - to some extent - a challenging issue [3].

\footnotetext{
* Correspondence: ahmedbaz2012@yahoo.com

${ }^{1}$ Diagnostic and Interventional Radiology Department, Kasr Aliny Hospital,

Cairo University, Cairo, Egypt

Full list of author information is available at the end of the article
}

Recently, magnetic resonance imaging (MRI) has obtained an eminent role in the diagnosis of different knee diseases, providing a safe imaging modality with multi-planner capabilities and at the same time not exposing the patient to ionizing radiation; moreover, it can help in an accurate assessment of the intra-articular structures like ligaments and cartilage as well as the extra-articular structures like tendons and the peri-articular musculature. It has been considered as a standard technique that could replace the diagnostic arthroscopy as a primary diagnostic modality for different knee problems, in addition to the recognition of the anatomical variants associated with the patellar instability [4].

AKP is considered as a nonspecific complaint that may encompass different etiologies including intra-articular and extra-articular causes, and the common differential diagnosis list is tabulated in Table 1; awareness of these causes may help in understanding the source of symptoms and may guide the imaging protocol in every patient.

\section{Aim of the work}

The main objective of our work is to review the most common causes of AKP, with emphasis on their MRI findings 
Table 1 Summarizing the differential diagnosis for the common causes of the AKP and their clinical presentations

\begin{tabular}{|c|c|}
\hline Cause & Clinical presentation \\
\hline Articular cartilage injury & $\begin{array}{l}\text { The patient may describe a history of trauma, } \\
\text { and the mechanical symptoms may occur if } \\
\text { a loose body is present. } \\
\text { May have effusion or have a tenderness of } \\
\text { the involved structure (e.g., femoral condyles, } \\
\text { patella). }\end{array}$ \\
\hline Chondromalacia patellae & $\begin{array}{l}\text { The patient may have a retro-patellar pain, } \\
\text { a history of trauma, or an effusion on the } \\
\text { examination. }\end{array}$ \\
\hline Hoffa's disease & $\begin{array}{l}\text { The patient may have a pain and } \\
\text { tenderness localized to infrapatellar } \\
\text { fat pad. }\end{array}$ \\
\hline Osgood-Schlatter disease & $\begin{array}{l}\text { The patient may have tenderness and/or } \\
\text { swelling at the insertion of the patellar } \\
\text { tendon at the tibial tubercle in an adolescent. }\end{array}$ \\
\hline Patellar instability/subluxation & $\begin{array}{l}\text { The patient may have an intermittent pain } \\
\text { with a sensation of instability or movement } \\
\text { of the patella. } \\
\text { May have a swelling or a locking can occur } \\
\text { with loose bodies. May have tenderness } \\
\text { over the medial retinaculum. }\end{array}$ \\
\hline Patellar tendinopathy & $\begin{array}{l}\text { The patient may have tenderness over } \\
\text { the tendon. } \\
\text { The tendon may be thickened if the } \\
\text { condition is chronic. }\end{array}$ \\
\hline Pes anserine bursitis & $\begin{array}{l}\text { The pain is usually described as medial } \\
\text { rather than anterior in location with } \\
\text { tenderness over the pes anserine bursa. }\end{array}$ \\
\hline Prepatellar bursitis & $\begin{array}{l}\text { May be medial or lateral to the patella; } \\
\text { if symptomatic, tenderness can be } \\
\text { demonstrated on examination. }\end{array}$ \\
\hline Plica synovialis & $\begin{array}{l}\text { The patient may have a characteristic } \\
\text { swelling anterior to the patella } \\
\text { following trauma. }\end{array}$ \\
\hline Quadriceps tendinopathy & $\begin{array}{l}\text { The patient may have tenderness over } \\
\text { the tendon. }\end{array}$ \\
\hline $\begin{array}{l}\text { Sinding-Larsen-Johansson } \\
\text { syndrome }\end{array}$ & $\begin{array}{l}\text { The patient may have tenderness at } \\
\text { the patellar tendon insertion in the } \\
\text { inferior pole of the patella in an } \\
\text { adolescent. }\end{array}$ \\
\hline Symptomatic bipartite patella & $\begin{array}{l}\text { The patient may have tenderness } \\
\text { directly over the patella with } \\
\text { characteristic radiographic findings. }\end{array}$ \\
\hline
\end{tabular}

to allow a more accurate diagnosis and grading of some of the most common pathologies of such common complaint.

\section{Methods}

Seventy patients were included in this study (24 males and 46 females). The patients' ages ranged from 10 to 53 years with a mean age \pm SD of $28.8 \pm 9.06$ years. All patients were referred to the radiology department in the time period from May 2014 to June 2015.

\section{Inclusion criteria}

Any patient complaining of an anterior knee pain and willingness to participate in the study.

\section{Exclusion criteria}

Patients who had absolute contraindications to MR examination such as a cardiac pacemaker and aneurismal clipping as well as patients who had a previous knee surgery and claustrophobic patients.

All patients were subjected to:

1- History taking including:

Personal history: it included the age, the sex, and the occupation

Present history: it included:

- Analysis of patient complaint (knee pain): site, onset, course, duration, and the relationship to posture

- Associated swelling, stiffness, and deformity

Past history of previous trauma or operations

2- Plain X-ray of the affected knee joint (if it was clinically indicated)

3- MRI of the affected knee

The local ethics committee approved the study, and all participants gave their informed consent before being included.

\section{MRI examination}

Most patients had MR imaging of the affected knee joints on high field strength scanners using Philips scanners Achieva or Intera $(1.5 \mathrm{~T})$; for MRI sequences parameters on high field strength scanners, see Table 2. MRI was performed by a knee coil in all cases.

\section{Technique}

\section{1- Positioning:}

The patients were positioned supine with the affected knee completely or nearly completely extended in the knee coil.

Table 2 Demonstrating the parameters of the MRI sequences on high field strength scanners (TR, time of repetition; $T E$, time of echo; STIR, short tau inversion recovery; FOV, field of view; PD, proton density; FFE, fast field echo)

\begin{tabular}{lllllll}
\hline Parameters & $\begin{array}{l}\text { Sagittal } \\
\text { T1 }\end{array}$ & $\begin{array}{l}\text { Sagittal } \\
\text { T2 }\end{array}$ & $\begin{array}{l}\text { Sagittal } \\
\text { STIR }\end{array}$ & $\begin{array}{l}\text { Sagittal } \\
\text { PD }\end{array}$ & $\begin{array}{l}\text { Coronal T2 } \\
\text { FFE }\end{array}$ & $\begin{array}{l}\text { Axial } \\
\text { T2 }\end{array}$ \\
\hline TR & 600 & 3600 & 2400 & 1620 & 380 & 3600 \\
TE & 17 & 100 & 60 & 30 & 13 & 100 \\
FOV & & & & & & \\
$\quad$ Anterior-posterior & 30 & 30 & 30 & 30 & 30 & 20 \\
Left-right & 35 & 35 & 50 & 35 & 50 & 60 \\
Feet-head & 50 & 50 & 20 & 50 & 20 & 40 \\
\hline
\end{tabular}


Table 3 Demonstrating the MRI grading of chondromalacia patella depending on the International Cartilage Repair Society (ICRS) and Outerbridge grading system [5]

\begin{tabular}{ll}
\hline Grade & MRI appearance \\
\hline II & Focally increased signal intensity but with preserved contour. \\
& $\begin{array}{l}\text { A swollen or frayed hyaline cartilage that may extend to the } \\
\text { surface but with }<50 \% \text { cartilage thickness loss. }\end{array}$ \\
III $\quad \begin{array}{l}>50 \% \text { hyaline cartilage thickness loss but with focal surface } \\
\text { ulceration of the hyaline cartilage. }\end{array}$ \\
IV $\quad \begin{array}{l}\text { Total loss of the hyaline cartilage thickness with underlying } \\
\text { reactive osseous changes. }\end{array}$
\end{tabular}

\section{2- Protocol:}

MRI imaging sequences:

The MRI study included some or all of the following pulse sequences:

- Sagittal T1 WIs

- Sagittal T2 WIs

- Sagittal PD WIs

- Sagittal STIR or PD fat saturation

- Axial T2WIs

- Axial STIR

- Coronal T2 FFE WIs or STIR
The following parameters were applied: the slice thickness was $4 \mathrm{~mm}$, the slice gap was $4 \mathrm{~mm}$, the matrix was $256 / 192$ or $512 / 224$, and the field of view ranged from 12 to $16 \mathrm{~cm}$.

The average duration time of the examination was from $25 \mathrm{~min}$ up to $30 \mathrm{~min}$.

All cases of chondromalacia patella had the grading system depending on the international cartilage repair society (ICRS) and Outerbridge grading system (Table 3) [5].

In suspected cases of patella alta, we used InsallSalvati index for the assessment of the patellar height, which was calculated as the length of the patellar ligament measured posteriorly from the distal end of the patella to its bony attachment in the tibial tuberosity, divided by the longest superoinferior dimension of the patella. Patella alta was defined when the patellar height ratio was more than 1.3 (normally it is 0.8 to 1.1) (Fig. 1) [6].

The trochlear dysplasia had been described as one of the predisposing factors of chronic patellofemoral instability. It had been classified into four types (A-D) (Table 4) (Figs. 2, 3, and 4) [5].

In cases of patellar maltracking, we measured the following different parameters for the assessment of the trochlear dysplasia.

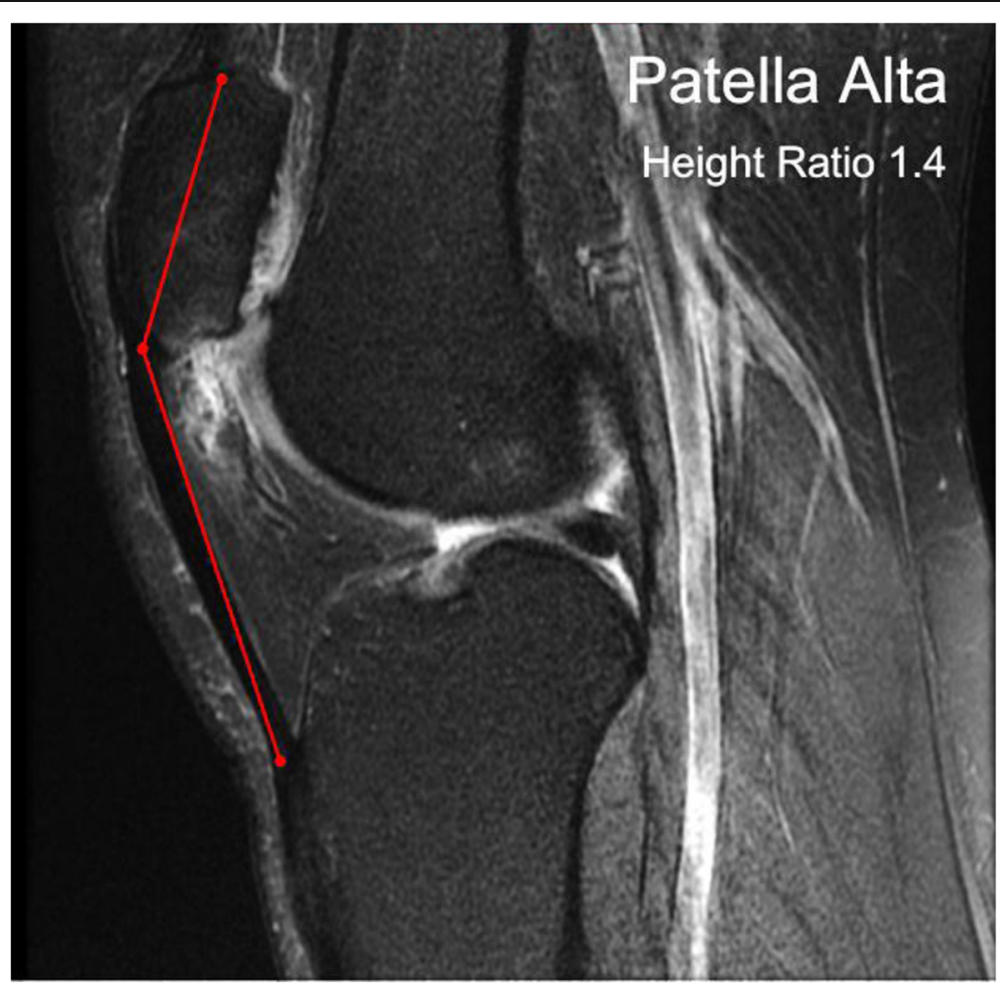

Fig. $1 \mathrm{MRI}$ image in sagittal STIR demonstrated how to assess the patella alta depending on Insall-Salvati ratio [6] 
Table 4 Demonstrating the classification of the trochlear dysplasia [7]

\begin{tabular}{ll}
\hline Type & Description \\
\hline A $\quad \begin{array}{l}\text { A trochlea with normal shape but with a shallow trochlear } \\
\text { groove }\end{array}$ \\
B $\quad \begin{array}{l}\text { Flattening of the trochlear groove mounting to a convexity } \\
\text { C } \quad \begin{array}{l}\text { Asymmetry of the trochlear facets showing a too high lateral } \\
\text { facet and a hypoplastic medial one with a resultant flattened }\end{array} \\
\text { articular surface in an oblique fashion } \\
\text { D Features like that in C type but with a longitudinal link } \\
\text { intervening the two facets giving the cliff pattern on the } \\
\text { parasagittal plane in MRI }\end{array}$ \\
\hline
\end{tabular}

1- Lateral trochlear inclination according to Carrillon et al. [8]; It was defined on the MR slices at about $3 \mathrm{~cm}$ proximal to the femorotibial cleft by measuring the angle between a line drawn tangential to the subchondral bone of the posterior aspects of the femoral condyles and a line tangential to the subchondral bone of the lateral trochlear facet (see Fig. 2).

2- Trochlear facet asymmetry according to Pfirrmann et al. [9]; MRI slices at about $3 \mathrm{~cm}$ proximal to the femorotibial cleft; the trochlear facet asymmetry was expressed with the relation of the length of the medial facet $(\mathrm{M})$ to the lateral facet $(\mathrm{L})$ and was expressed as a percent using the following equation $([\mathrm{M} / \mathrm{L}] \times 100 \%)($ see Fig. 3).

3- Depth of the trochlear groove according to Pfirrmann et al. [9]; MRI slices at about $3 \mathrm{~cm}$ proximal to the femorotibial cleft; the trochlear depth was assessed by measuring the maximal anteroposterior distance of the medial (line A) and lateral femoral (line B) condyles and the minimal anteroposterior distance between the deepest point of the trochlear sulcus (line $\mathrm{C}$ ) and the line drawn tangential to the posterior outlines of the femoral condyles (line D). The trochlear depth was calculated by the equation $([\mathrm{A}+\mathrm{B}] / 2)-\mathrm{C}$ (see Fig. 4).

\section{Statistical methods}

Data were coded and entered using the statistical package SPSS version 25. Data were summarized using mean, standard deviation, median, minimum, and maximum for quantitative variables and frequencies (number of cases) and relative frequencies (percentages) for categorical variables.

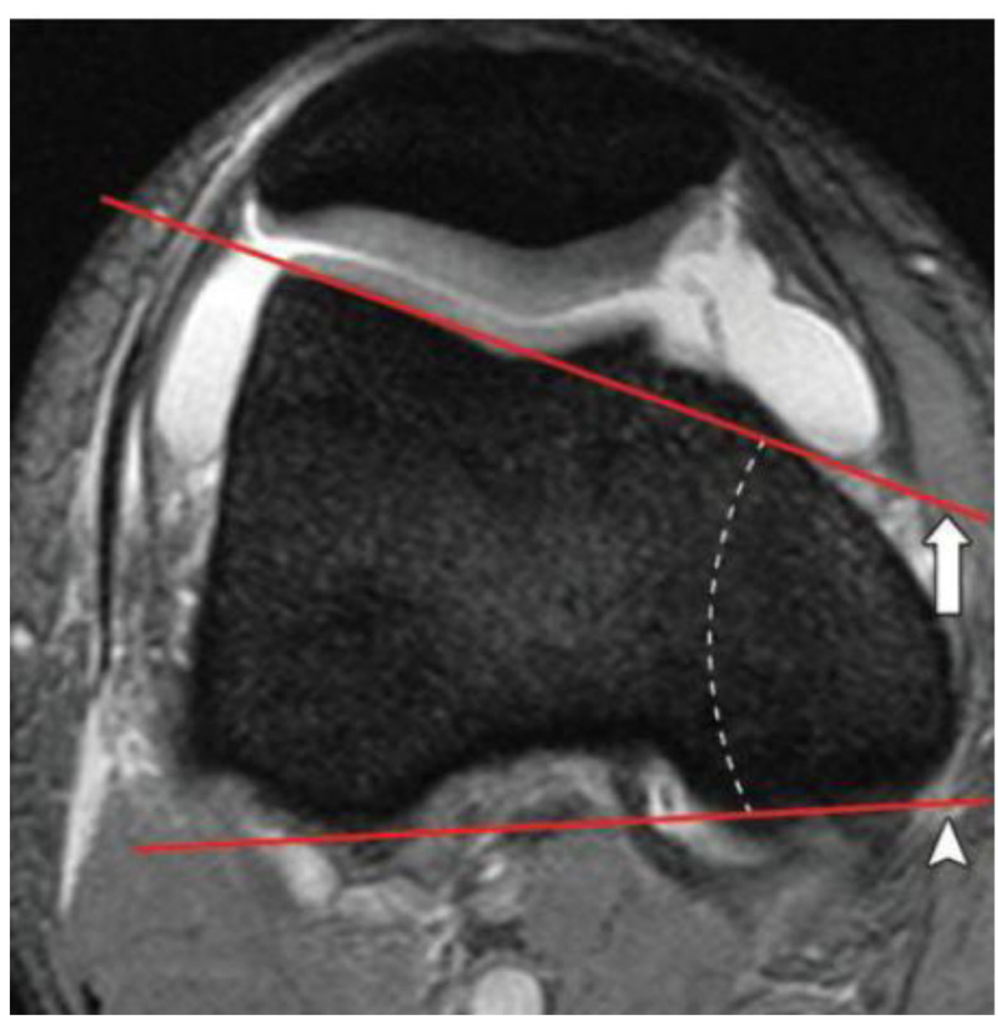

Fig. 2 Axial fat-saturated T2-weighted MR image for the assessment of the lateral trochlear inclination angle. The first line (arrow) was drawn tangential to the subchondral bone of the lateral trochlear facet, and a second line (arrowhead) was drawn tangential to the posterior aspect of the femoral condyles. The angle between the two lines was defined as the inclination angle (white dashed line). An inclination angle $<11^{\circ}$ was considered as an indicator of trochlear dysplasia [8] 


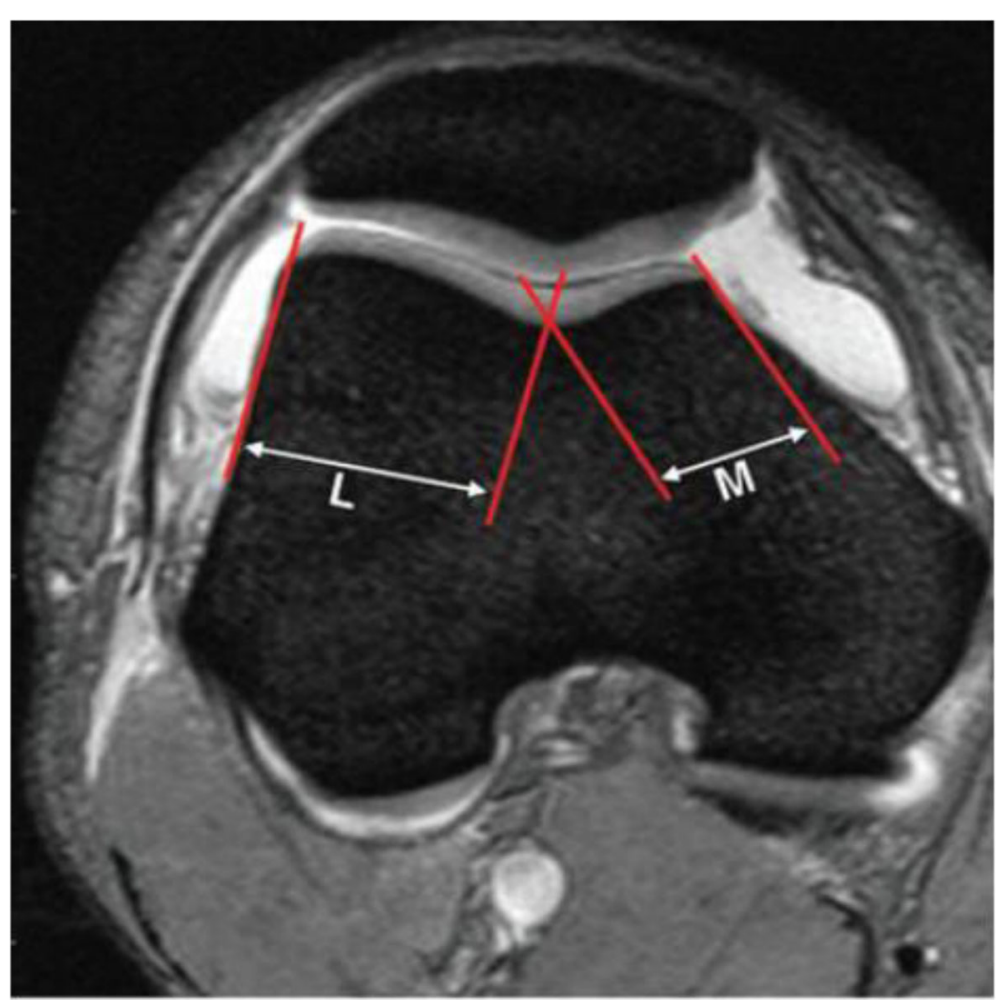

Fig. 3 Axial fat-saturated T2-weighted MR image for assesment of the asymmetry of the femoral trochlear facets. The percentage of the asymmetry of the medial facet $(\mathbf{M})$ and the lateral facet $(\mathbf{L})$ lengths was calculated as $(\mathrm{M} / \mathrm{L} \times 100 \%)$. A trochlear facet asymmetry ratio $<40 \%$ was considered as an indicator of trochlear dysplasia [9]

\section{Results}

Seventy patients were included in the study (24 males (34\%) and 46 females (66\%)). The patients' ages ranged from 10 to 53 years with a mean age \pm SD of $28.8 \pm 9.06$ years.

Eleven disease entities were found among the patients in this study sample; the patellar causes were the dominating one ( $70 \%$ of cases), where the chondromalacia patella being found in $43 \%$ of cases $(n=$ 30) (Fig. 5), the patellar instability was found in 19\% of patients $(n=13)$, the transient patellar dislocation was found in 7\% of cases $(n=5)$ (Figs. 6 and 14), patellar tendinopathy was found in $4 \%$ of cases $(n=3)$ (Fig. 7), and the symptomatic bipartite patella was found in $1 \%$ of cases $(n=1)$ (Fig. 6). Hoffa's disease was found in $14 \%$ of cases $(n=10)$ (Figs. 8 and 9); the anterior meniscal tear was found in $13 \%$ of cases $(n=9)$ (Fig. 10) (Tables 5, 6, and 8).

Quadriceps tendon causes represented (7\% of cases) where the tendinopathy was found in $3 \%$ of cases $(n=2)$ (Fig. 11) and the quadriceps tendon tear was found in $4 \%$ of cases $(n=3)$ (Tables 5,6 , and 8 ).

Cartilage disease was found in $6 \%$ of cases $(n=4)$, Osgood-Schlatter disease was found in $4 \%$ of cases $(n=3)$ (Fig. 12) (Tables 5, 6, and 8).
The coexistence of more than one disease in one patient was found in 13 cases (18.5\%), and this was demonstrated in Table 7.

In this study, the female gender showed more affection in certain disease entities like chondromalacia patella, Hoffa's disease, patellar instability, patellar dislocation, patellar tendinopathy, quadriceps tendon tear, and the anterior meniscal tear, whereas the male gender showed more affection in the rest of the disease entities (Tables 5 and 8).

Chondromalacia patella was found in 30 patients (43\%); among them, there were 13 patients who had grade IV of the disease and 8 patients had grade III, 7 patients had grade II, and two patients had grade I (Table 9).

Trochlear dysplasia was found in 13 cases; among them, 5 cases had type A and 5 cases had type B while type C was found in 3 cases (Table 10); the trochlear groove depth measured in millimeter, the percentage of the facet asymmetry, and the lateral inclination angle were measured in each type of the trochlear dysplasia (Figs. 13, 14, and 15) being statistically calculated in minimum, maximum, median, and mean values (Table 11).

Patellar dislocation was found in 18 cases; among them, 13 cases had patellar instability while 5 cases had a transient patellar dislocation (Figs. 6, 13, 14, and 15) (Table 12). 


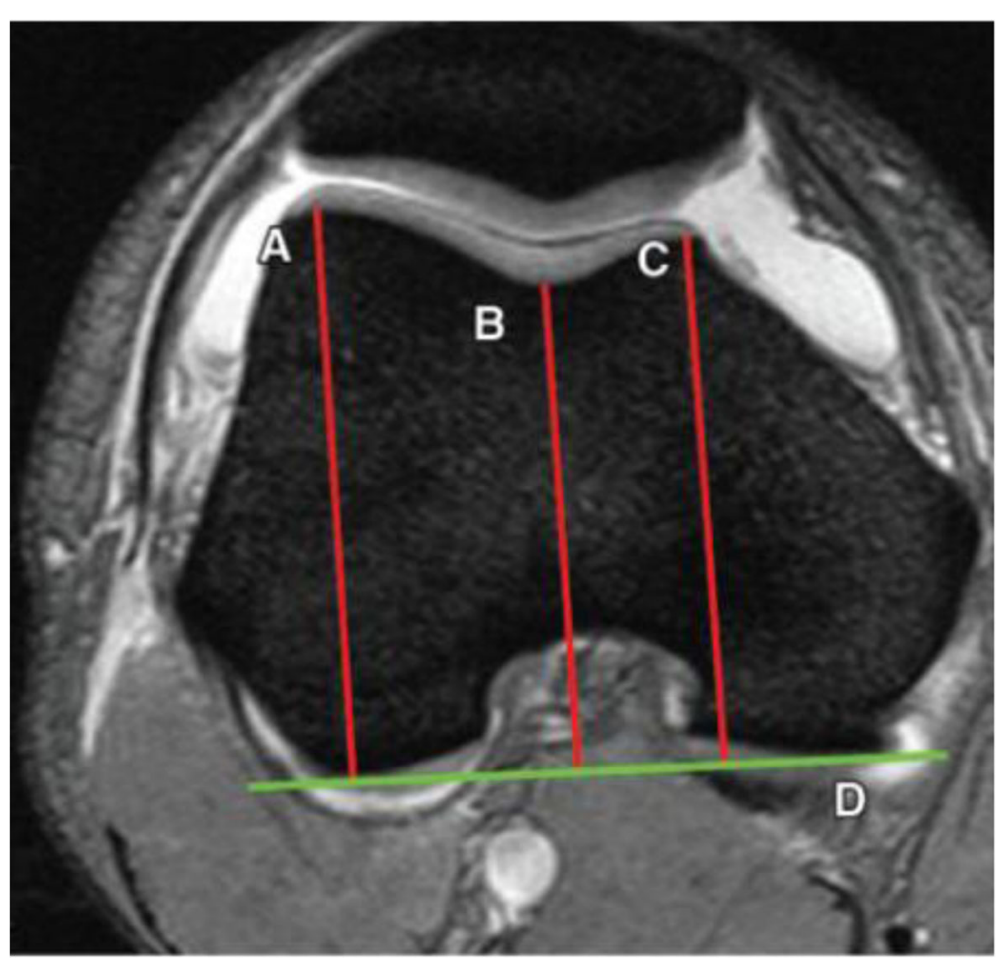

Fig. 4 Axial fat-saturated T2-weighted MR image for assessment of the trochlear; a line was drawn tangential to the posterior aspect of the femoral condyles and was considered as a reference line (line $\mathbf{D}$ ). The lines were drawn perpendicularly to the (line $\mathbf{D}$ ) and indicated the longest anteroposterior diameters of the lateral (line $\mathbf{A}$ ) and medial (line $\mathbf{C}$ ) trochlear facets and the deepest point of the trochlear groove (line $\mathbf{B}$ ). The femoral trochlear depth was calculated as $(A+C / 2)-B$. A trochlear depth of $3 \mathrm{~mm}$ or less was considered as an indicator of trochlear dysplasia [9]

\section{Discussion}

Diederichs, Issever, and Scheffler [7] reported that the AKP may affect up to more than $30 \%$ of adolescents at any time. The majority of their patients were female, and their symptoms most commonly occurred in their second and third decades of life; this was matching the present study where about $66 \%$ of the study sample was females with an average age of 27 years and $34 \%$ were males with an average age of 30 years.
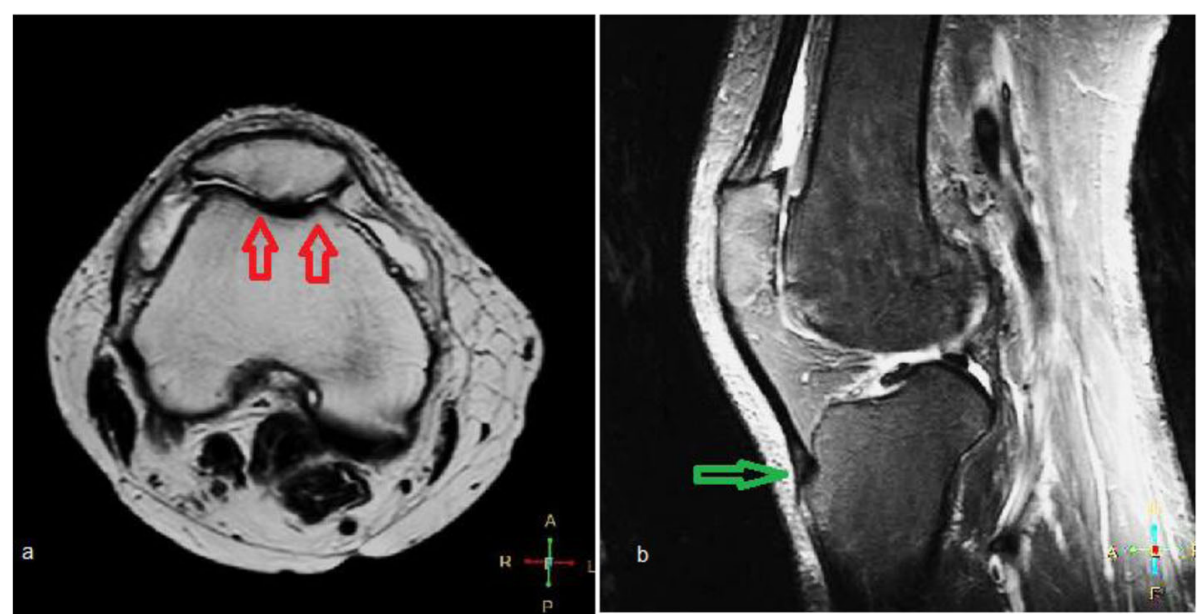

Fig. 5 a, b MRI images for grade IV chondromalacia patella with infrapatellar tendinopath.. a Axial T2-weighted image. b Sagittal PD fat suppression demonstrated diffuse full-thickness articular cartilage loss associated with subtle subchondral bone marrow edema (red open arrows). Note the high signal within the patellar tendon at the tibial tuberosity attachment (green open arrow) 


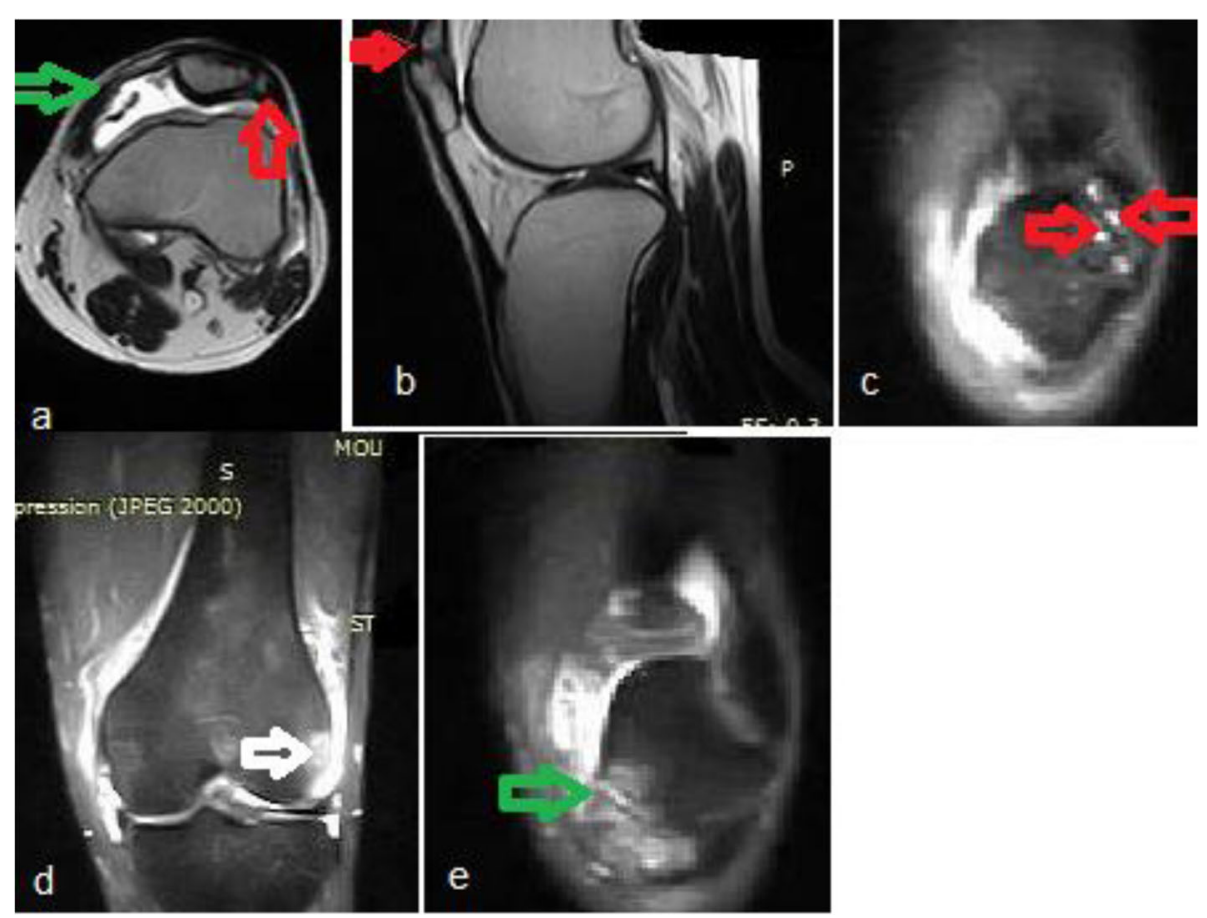

Fig. 6 a-e MRI images for the third type bipartite patella with degenerative changes at the synchondrosis and transient patellar dislocation. a Axial, $\mathbf{b}$ sagittal. and $\mathbf{c}$ coronal STIR images demonstrated a well-corticated non united fragment along the superolateral part of the patella (red arrows in $\mathbf{a}$ and $\mathbf{b}$ ); also note the pseudocysts at the opposing surfaces of the synchondrosis (open red arrows in $\mathbf{c}$ ) and the medial patellar retinaculum with an intra-substance bright signal (green arrow in a). d, e Coronal STIR WIs demonstrated kissing bone contusions at the lateral femoral condyle (open white arrow in $\mathbf{d}$ ) and medial facet of the patella (open green arrow in $\mathbf{e}$ )

In our study, we divided the pathological process causing the symptoms of anterior knee pain in a fashion similar to that proposed by McNally et al. [10] into five categories according to the location and the anatomical structure affected as follows: (a) patellar tendon disorders, (b) quadriceps tendon disorders, (c) patellar disorders, (d) Hoffa's diseases, and (e) miscellaneous causes including anterior meniscal tear and cartilage injuries.
In the present study, each category represented the following percentages: (a) Patellar tendon disorders represent $9 \%$ of the sample size, and they include patellar tendinopathy at $4 \%$ and Osgood-Schlatter disease at 4\%. (b) Quadriceps tendon disorders represent $7 \%$ of the sample size, and they include quadriceps tendinopathy at 3\% and quadriceps tendon tear at $4 \%$. (c) Patellar disorders represented $67 \%$ of the sample size, and they include chondromalacia

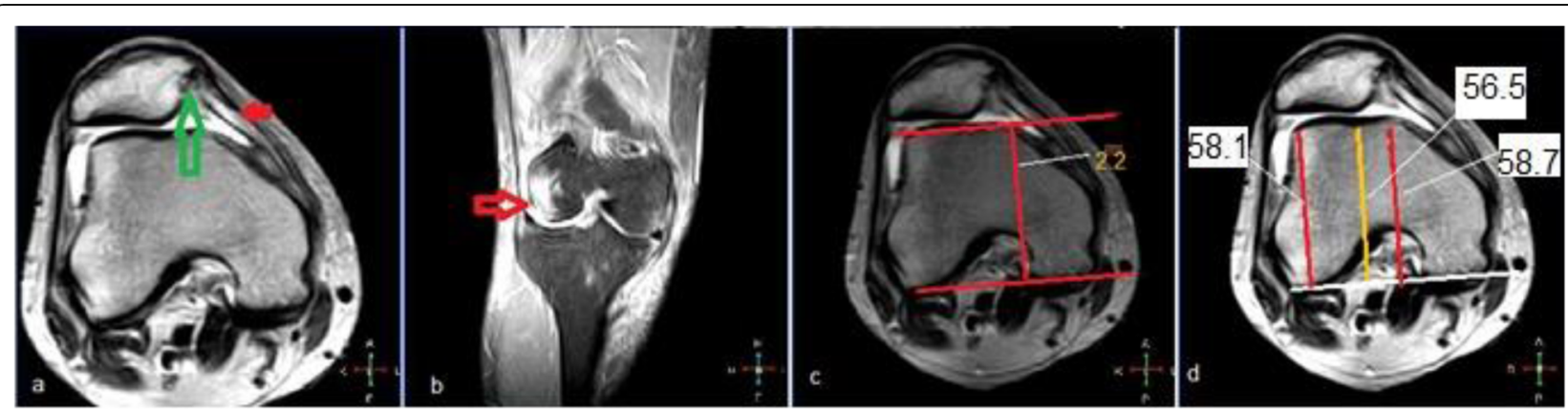

Fig. 7 a-d MRI images for transient patellar dislocation with kissing bone contusions of the medial patellar facet and lateral femoral condyle and an interstitial tear of the medial patellar retinaculum as well as a trochlear dysplasia type B (predisposing factor). a Axial T2WI demonstrated fluid signal within the thickened medial patellar retinaculum (red arrow) and medial patellar surface osteochondral injury (green arrow). b Coronal STIR demonstrated a bright signal at the lateral femoral condyle (bone contusion) (red arrow). c, d Axial T2Wls demonstrated a trochlear depth of about $2 \mathrm{~mm}$ and a lateral inclination angle of $2.2^{\circ}$ 

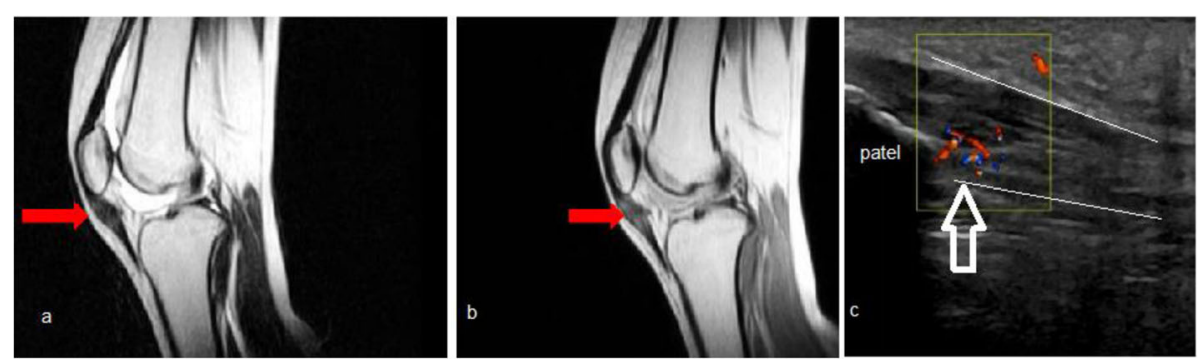

Fig. 8 a, b MRI images. c Color Doppler ultrasound image for infrapatellar tendinopathy. a Sagittal PD and $\mathbf{b}$ sagittal T2-weighted images demonstrated thickened infrapatellar tendon at its patellar attachment with an intra-substance areas of intermediate T1 and T2 signal intensity with no evidence of total discontinuity (red arrows) c showing thickening of the tendon (between the white lines) with intra-tendinous hyperemia (open white arrow)

patella at $43 \%$, patellar instability at $19 \%$, transient patellar dislocation at $7 \%$, and the painful bipartite patella at $3 \%$. (d) Hoffa's diseases represented $14 \%$ of the sample size, and they include Hoffa impingement syndrome and Hoffa ganglion cyst. Finally, (e) the miscellaneous causes that represented $17 \%$ of the sample size, and they include torn anterior horn of the lateral meniscus at $13 \%$ and articular cartilage shear injury at $4 \%$ (Tables 5 and 8).

Patellar tendinitis (PT) or Jumper's knee is considered as one of the most common tendon abnormalities in young active subjects. From the etiological point of view, it had been recently described as a degenerative tendinopathy rather than an inflammatory process [11]. It exhibits the characteristic imaging features in MRI including focal thickening of the proximal segment of the tendon (the tendon AP thickness is more than $7 \mathrm{~mm}$ ) that may show an area of focal T2 high signal intensity, with a predilection to the medial portion of the affected tendon [12].

In our results, $4 \%$ of the patients presented with AKP showed MRI evidence of patellar tendinopathy ( $66 \%$ below the age of 30 years). In all cases, the hyperintense focal thickening was at the proximal third of the tendon, with the AP diameter of the patellar tendon being greater than $8 \mathrm{~mm}$ (Fig. 7), and this was concordant with the study of Mohammad Samim et al. [12], as regards the MRI findings of patellar tendinitis.

Osgood-Schlatter disease (OSD) was defined by Gottsegen et al. [13], as a traction apophysitis of the tibial tuberosity caused by repetitive microtrauma. It is more prevalent in adolescent male athletes.

Niitsu [14] considered the MRI as the modality of choice for the diagnosis of OSD as the tibial surface may not be yet ossified; thus, the plain radiography may play a limited role in the diagnosis of the early

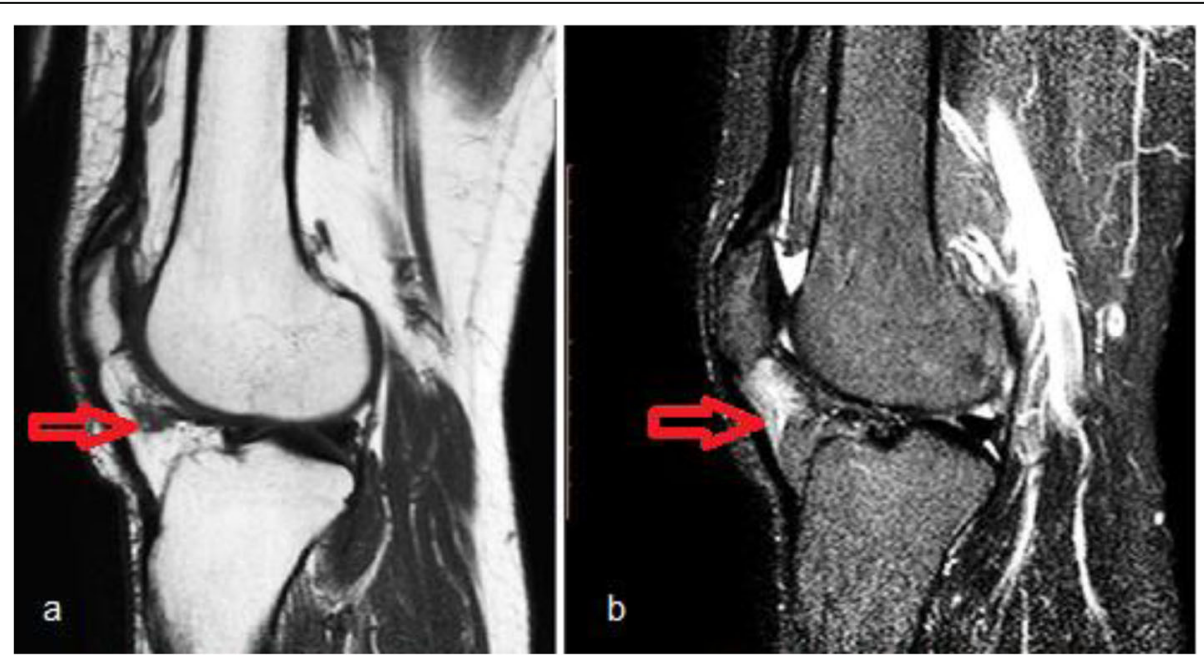

Fig. 9 a, b MRI images for infrapatellar fat pad impingement syndrome. a Sagittal T1WI and $\mathbf{b}$ sagittal PD fat suppression images demonstrated edema involving a significant portion of the infrapatellar fat pad (red open arrows) 


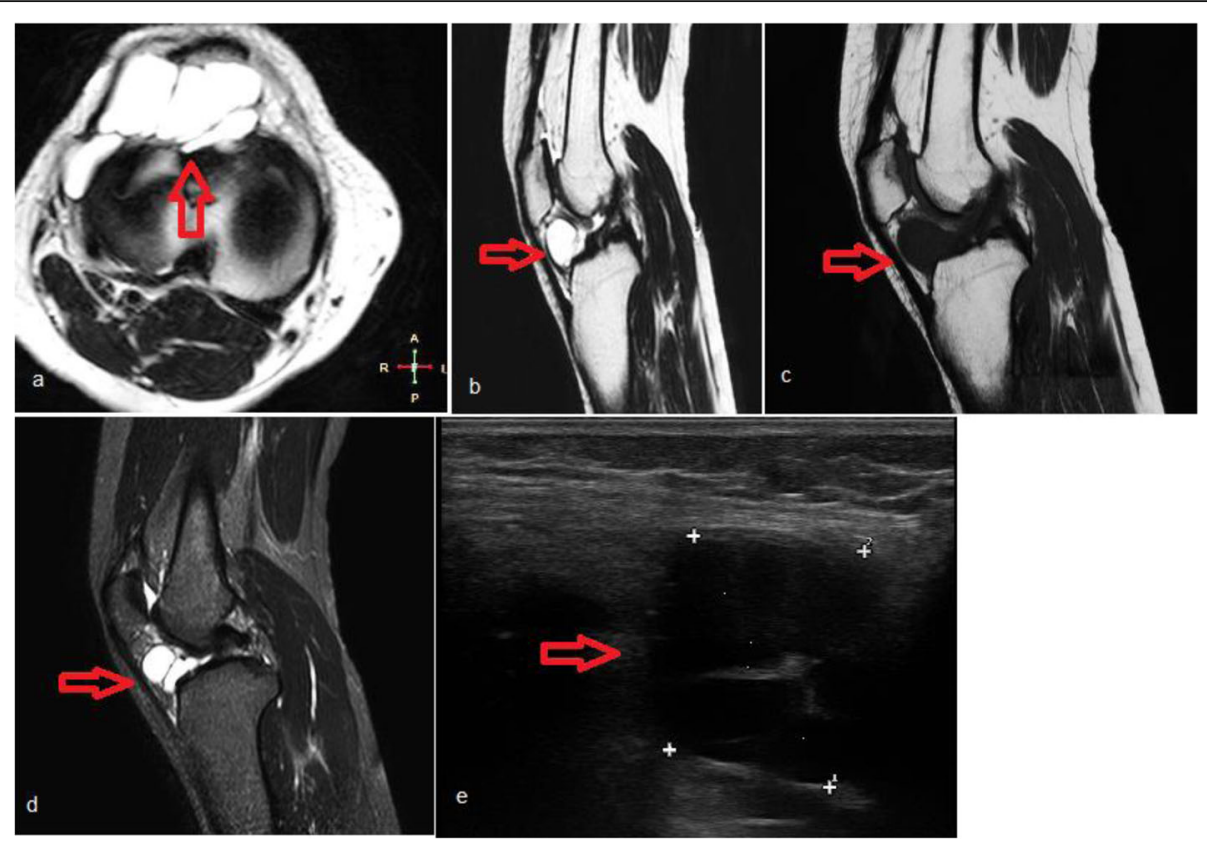

Fig. 10 a-d MRI images and e a high-resolution ultrasound image for Hoffa's pad fat ganglion cyst. a Axial T2WI, b sagittal T2Wl, c sagittal T1WI, and $\mathbf{d}$ sagittal PD fat suppression demonstrated a large well-defined lobulated intra-articular cystic lesion within the infrapatellar fat pad. It elicited a low signal on T1WI and a bright signal on T2WI and PD fat suppression (red open arrows). e B-mode image demonstrated anechoic lobulated and septated Hoffa's pad fat cyst concordant with the MRI findings

cases. In our study, about $4 \%$ had an MRI evidence of OSD (all of them were < 30 years) (Fig. 12), with a male predominance in the study sample (males represented $67 \%$ of OSD sample size).

Aparicio et al. [15] had related the presence of a patella alta (patellar height ratio of more than 1.3) (normal is 0.8 to 1.1 ) as one of the predisposing factors to OSD; in our results, $33 \%$ of the cases showed MRI evidence of patella alta (patellar height ratio equal to 1.7) as a predisposing factor for OSD (Fig. 15).

Table 5 Demonstrating the number (No.) and the percentage (\%) of the prevalence of different causes of anterior knee pain (AKP) by sex

\begin{tabular}{lllll}
\hline Patients & & Total number & Female & Male \\
\hline Patellar causes & No. & 47 & 32 & 15 \\
& $\%$ & $70 \%$ & $68 \%$ & $32 \%$ \\
Hoffa disease & No. & 10 & 7 & 3 \\
Miscellaneous & $\%$ & $14 \%$ & $70 \%$ & $30 \%$ \\
& No. & 12 & 7 & 5 \\
Quadriceps tendon causes & $\%$ & $18 \%$ & $58 \%$ & $42 \%$ \\
& No. & 5 & 3 & 2 \\
Patellar tendon causes & $\%$ & $7 \%$ & $60 \%$ & $40 \%$ \\
& No. & 6 & 3 & 3 \\
& $\%$ & $9 \%$ & $50 \%$ & $50 \%$ \\
\hline
\end{tabular}

Quadriceps tendon rupture is one of the serious extensor tendon injuries, and its incidence had been reported as an uncommon problem; it is more seen in subjects older than 40 years. When it occurs, it usually takes place at the tendon-bone junction and may be a partial or a full-thickness tear; nevertheless,

Table 6 Demonstrating the prevalence of 11 diseases entities found among the patients in the study sample. This table showed the largest percentage of the patients suffered from the chondromalacia patella

\begin{tabular}{|c|c|c|c|c|}
\hline & \multicolumn{2}{|c|}{ Disease not existing } & \multicolumn{2}{|c|}{ Disease existing } \\
\hline & No. & $\%$ & No. & $\%$ \\
\hline Chondromalacia patella & 40 & $57 \%$ & 30 & $43 \%$ \\
\hline Hoffa's disease & 60 & $86 \%$ & 10 & $14 \%$ \\
\hline Patellar instability & 57 & $81 \%$ & 13 & $19 \%$ \\
\hline Transient patellar dislocation & 65 & $93 \%$ & 5 & $7 \%$ \\
\hline Quadriceps tendinopathy & 68 & $97 \%$ & 2 & $3 \%$ \\
\hline Quadriceps tendon tear & 67 & $96 \%$ & 3 & $4 \%$ \\
\hline Patellar tendinopathy & 67 & $96 \%$ & 3 & $4 \%$ \\
\hline Osgood-Schlatter disease & 67 & $96 \%$ & 3 & $4 \%$ \\
\hline Cartilage injury & 66 & $94 \%$ & 4 & $6 \%$ \\
\hline Bipartite patella & 69 & $99 \%$ & 1 & $1 \%$ \\
\hline Anterior meniscal tear & 61 & $87 \%$ & 9 & $13 \%$ \\
\hline Sum & & & 83 & \\
\hline
\end{tabular}




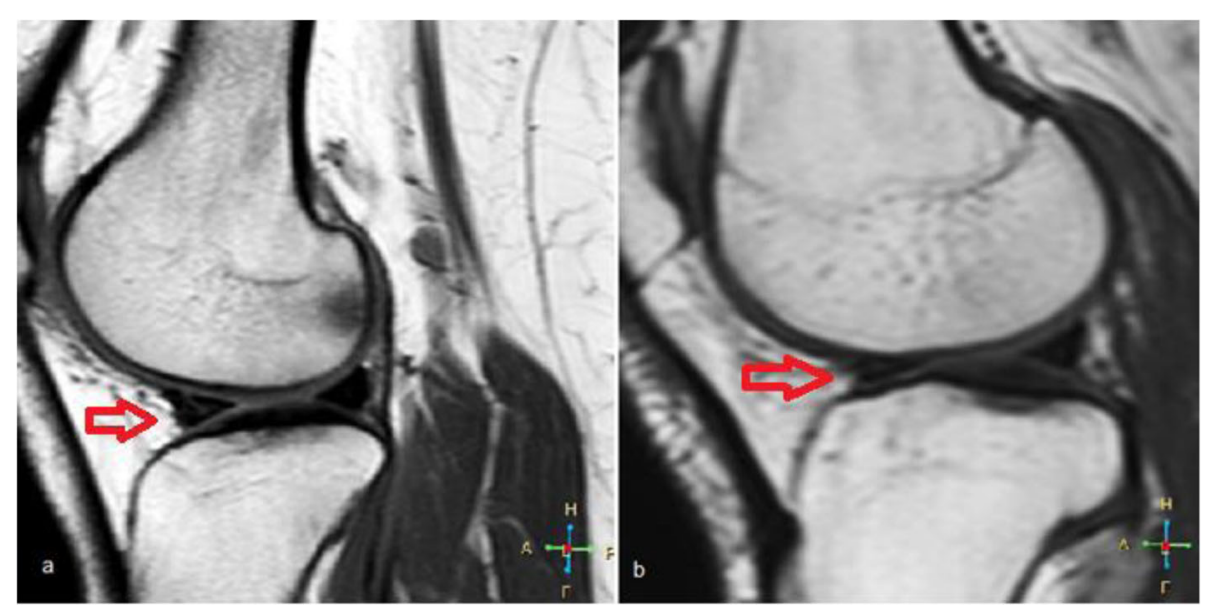

Fig. 11 a, b MRI images for torn anterior horn of the medial meniscus. a Sagittal PD and $\mathbf{b}$ sagittal T1-weighted images demonstrated a branching band of abnormal signal within the anterior horn of the lateral meniscus that was seen reaching to both articular surfaces (open red arrows)

the partial thickness tear may be challenging for clinical diagnosis as there is some preservation of the extensor mechanism; hence, the MRI may play an important role in its early detection [16]. In our results, $4 \%$ (3 patients) had a quadriceps tendon rupture; 2 of them were above the age of 40 years; also, 2 of them showed MRI evidence of partial tear and one patient showed MRI evidence of complete tendon tear with all fibers were transected. All of these patients experienced a past history of trauma, and none of them had a predisposing factor for spontaneous tendon rupture.

The alteration of the biomechanics of the tendon can lead to tendon degeneration resulting in chronic tendinosis that may present by AKP [17]; in MRI, it may appear as a chronic enthesopathy; in our results, the quadriceps tendinopathy was detected in about $3 \%$ of the patients who presented by AKP.

Chondromalacia patella could be described as a denudation of the patellar cartilage with surface irregularity on arthroscopic probing; this condition may present patellofemoral pain (PFP) and is more likely to be seen in adolescents especially the females [18]; this was matched with our study where $(70 \%$ female, $30 \%$ male, and 25 years age average). Considering the 0.05 level of significance, the $P$ value of chi-square test (0.03) showed that there was a significant difference between the prevalence of chondromalacia patella between males and females.

The degree of cartilage loss can be graded into four degrees by arthroscopy according to the Outerbridge grading system; however, the International Cartilage

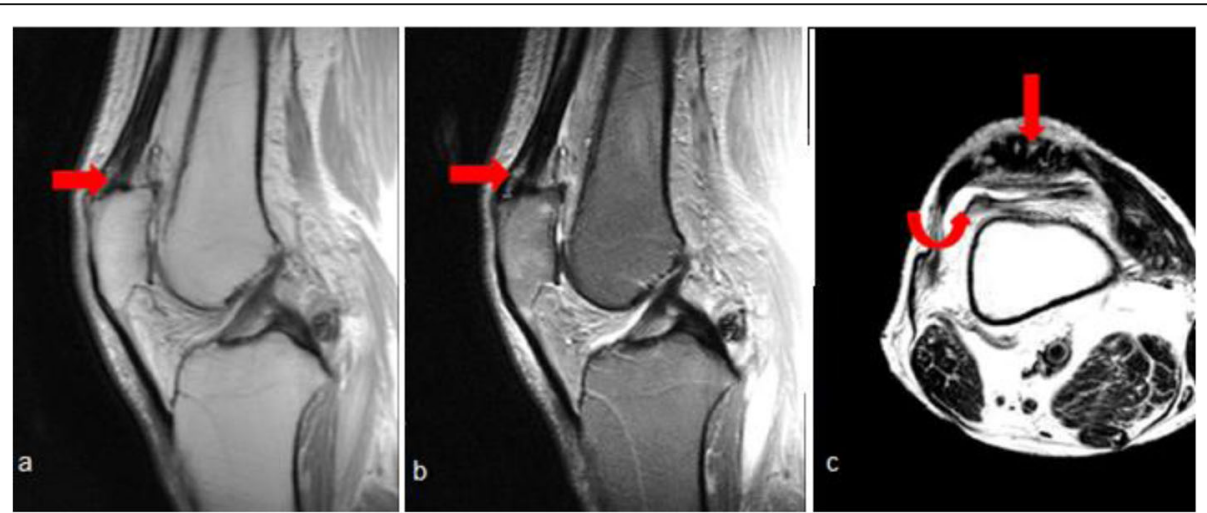

Fig. 12 a-c MRI images for quadriceps tendinopathy. a Sagittal PD weighted and $\mathbf{b}$ PD fat suppression demonstrated high signal intensity within the quadriceps tendon at the patellar attachment. c Axial T2-weighted image demonstrated a high signal intensity within the quadriceps tendon (red arrows) as well as a minimal amount of joint effusion (curved red arrow) 
Table 7 Demonstrating the overlapping between patients who had more than one disease entity

\begin{tabular}{|c|c|c|c|c|c|c|c|}
\hline & Hoffa disease & Patellar instability & Cartilage Injury & Anterior meniscal tear & Patellar tendinopathy & $\begin{array}{l}\text { Transient patellar } \\
\text { dislocation }\end{array}$ & Sum \\
\hline Chondromalacia patella & 5 & 1 & 1 & & & & 7 \\
\hline Patellar instability & 1 & & 1 & 1 & & & 3 \\
\hline Anterior meniscal tear & & & & & 1 & & 1 \\
\hline Bipartite patella & & & & & & 1 & 1 \\
\hline Osgood-Schlatter disease & & & & & & 1 & 1 \\
\hline Sum & 6 & 1 & 2 & 1 & 1 & 2 & 13 \\
\hline
\end{tabular}

Repair Society (ICRS) found a good MRI correlation to the Outerbridge grading system and classified the cartilage loss into four degrees as well (Table 3) $[19,20]$.

Mattila et al. [20] reported that the MRI diagnostic accuracy is higher for high-grade lesions (grades III and IV), and this was greatly matching our study, where $43 \%$ of the cases of chondromalacia patella were grade IV, $27 \%$ were grade III, $23 \%$ were grade II, and $7 \%$ were grade I (Table 9).

MRI plays an important role in the diagnosis of the patellar instability; moreover, it can provide a clue for

Table 8 Demonstrating the percentage of sex prevalence among different diseases entities

\begin{tabular}{|c|c|c|c|c|}
\hline & & Female & Male & Sum \\
\hline \multirow[t]{2}{*}{ Chondromalacia patella } & No. & 21 & 9 & 30 \\
\hline & $\%$ & $70 \%$ & $30 \%$ & \\
\hline \multirow[t]{2}{*}{ Hoffa's disease } & No. & 7 & 3 & 10 \\
\hline & $\%$ & $70 \%$ & $30 \%$ & \\
\hline \multirow[t]{2}{*}{ Chronic patellar instability } & No. & 9 & 4 & 13 \\
\hline & $\%$ & $69 \%$ & $31 \%$ & \\
\hline \multirow[t]{2}{*}{ Transient patellar dislocation } & No. & 3 & 2 & 5 \\
\hline & $\%$ & $60 \%$ & $40 \%$ & \\
\hline \multirow[t]{2}{*}{ Quadriceps tendinopathy } & No. & 1 & 1 & 2 \\
\hline & $\%$ & $50 \%$ & $50 \%$ & \\
\hline \multirow[t]{2}{*}{ Quadriceps tendon tear } & No. & 2 & 1 & 3 \\
\hline & $\%$ & $67 \%$ & $33 \%$ & \\
\hline \multirow[t]{2}{*}{ Patellar tendinopathy } & No. & 2 & 1 & 3 \\
\hline & $\%$ & $67 \%$ & $33 \%$ & \\
\hline \multirow[t]{2}{*}{ Osgood-Schlatter disease } & No. & 1 & 2 & 3 \\
\hline & $\%$ & $33 \%$ & $67 \%$ & \\
\hline \multirow[t]{2}{*}{ Cartilage injury } & No. & 1 & 3 & 4 \\
\hline & $\%$ & $25 \%$ & $75 \%$ & \\
\hline \multirow[t]{2}{*}{ Bipartite patella } & No. & 0 & 2 & 2 \\
\hline & $\%$ & $0 \%$ & $100 \%$ & \\
\hline \multirow[t]{2}{*}{ Anterior meniscal tear } & No. & 6 & 3 & 9 \\
\hline & $\%$ & $67 \%$ & $33 \%$ & \\
\hline
\end{tabular}

the diagnosis of the anatomical variants that may predispose to the condition [21].

The study done by Kirsch et al. had found that the prevalence of patellar dislocation among 1450 patient was $2 \%$. The most constant finding detected in all of the patients with transient patellar subluxation was the presence of knee effusion (100\%). Abnormalities in the medial patellar retinaculum were found in about $96 \%$, and abnormal lateral patellar position in about 92\%, whereas the contusions of the outer femoral condyle and the inner patellar facet were found in about $81 \%$ [22].

In our study, the patellofemoral instability (i.e., transient patellar dislocation) was detected in $7 \%$ of the patients who were presented by AKP, with female predominance ( $60 \%$ female and $40 \%$ male); almost all patients had MRI evidence of joint effusion, and also almost all of them showed abnormalities in the medial patellar retinaculum. Eighty percent of our patients showed abnormal lateral patellar position and $60 \%$ of them showed contusions of the outer femoral condyle and the inner patellar facet (kissing contusions).

Trochlear dysplasia had been described as a predisposing factor for patellar instability and was classified into four main types by Dejour and Coultre [23] (types A, B, C, and D) (Table 4).

In our study, we founded that $19 \%$ of the patients had PFP with malalignment (i.e., chronic patellar instability) and showing MRI evidence of trochlear dysplasia. Thirty-eight percent were categorized as type A, 38\% as

Table 9 Demonstrating the percentage of the prevalence of the different grades of chondromalacia patella

\begin{tabular}{llllll}
\hline & $\begin{array}{l}\text { Grade } \\
\text { I }\end{array}$ & $\begin{array}{l}\text { Grade } \\
\text { II }\end{array}$ & $\begin{array}{l}\text { Grade } \\
\text { III }\end{array}$ & $\begin{array}{l}\text { Grade } \\
\text { IV }\end{array}$ & $\begin{array}{l}\text { Grand } \\
\text { Total }\end{array}$ \\
\hline $\begin{array}{l}\text { No. of chondromalacia } \\
\text { patella patients }\end{array}$ & 2 & 7 & 8 & 13 & 30 \\
$\begin{array}{l}\text { Percentages of } \\
\text { chondromalacia patella } \\
\text { patients }\end{array}$ & $7 \%$ & $23 \%$ & $27 \%$ & $43 \%$ & $100 \%$ \\
\hline
\end{tabular}


Table 10 Demonstrating the percentage of the different grades of trochlear dysplasia among the patients with patellar instability

\begin{tabular}{lllll}
\hline & Type A & Type B & Type C & $\begin{array}{l}\text { Grand } \\
\text { total }\end{array}$ \\
\hline $\begin{array}{l}\text { No. of trochlear dysplasia patients } \\
\begin{array}{l}\text { Percentages of trochlear-dysplasia } \\
\text { patients }\end{array}\end{array}$ & $38 \%$ & 5 & 3 & 13 \\
\hline
\end{tabular}

type B, and $24 \%$ as type C according to Dejour et al.'s classification (Figs. 13, 14, and 15) (Table 10).

For the assessment of the trochlear dysplasia, the lateral trochlear angle inclination was instrumented using the MRI by Carrillon et al. [8]; they found the lateral trochlear inclination of $11^{\circ}$ to be a threshold value to distinguish between patients with patellofemoral instability (trochlear dysplasia) and those with a nonspecific knee pain.

Another method was by measuring the depth of the trochlear groove and the trochlear facet asymmetry being measured $3 \mathrm{~cm}$ proximal to the tibiofemoral cleft; this was described by Pfirrmann et al. [9] who found that trochlear groove depth less than $3 \mathrm{~mm}$ and facet asymmetry of less than $40 \%$ were of diagnostic value for the trochlear dysplasia.

MRI had been proved to be highly accurate with reproducible measurement of the femoral sulcus from the subchondral bone as well as from the articular hyaline cartilage as the measurements from the articular cartilage was considered a true measurement rather than the plain radiography measurements as the former is more representative of the actual joint space [7].

Nelitz et al. did a study on 80 knees of 78 patients, aiming to evaluate whether specific measurements of the femoral trochlea can be assigned to the qualitative classification system of Dejour using the abovementioned measurements. They concluded that, by using a descriptive statistics using boxplot diagrams, none of the objective measurements of the femoral trochlea described in the literature could be assigned to the four-grade descriptive classification of trochlear dysplasia of Dejour as the median and average range of these measurements allowed no discrimination between trochlear dysplasia types B, C, and D. However, the threshold values used to discriminate between low-grade (Dejour type A) and high-grade dysplasia (Dejour types B-D) could be identified [24].

In our results, types $\mathrm{B}$ and $\mathrm{C}$ trochlear dysplasia showed nearly similar median and average values of both the trochlear groove depth and lateral inclination angle (median value of trochlear groove depth for both $B$ and $C$ was $2 \mathrm{~mm}$ and for $A$ was $5 \mathrm{~mm}$; the median values of the lateral inclination angles for both $\mathrm{B}$ and $\mathrm{C}$ were $9^{\circ}$ and $9.4^{\circ}$ respectively and for type A was $20^{\circ}$ ). The median values of the trochlear facet asymmetry were different between different types of trochlear dysplasia (the median value for type A was $39 \%$, for type B was $55 \%$, and for type C was 33\%) (Table 11).

Fithian et al. [25] also reported that most patients with patellar dislocation were young and active subjects, with the females in their 2nd decade of life being considered as a more vulnerable group. In our study, we found that $66 \%$ of the patients were female and $34 \%$ of them were male.

An association between the patellar subluxation with both the chondromalacia patella and the patellar tendinopathy had been found by McNally et al. [26]; in our results, only $7 \%$ of the patients with patellar subluxation had MRI evidence of a chondromalacia patella and $7 \%$ had MRI evidence of patella Alta (Fig. 15).

Bipartite patella occurs when the secondary ossification centers of the patella did not fuse together; Mohammad Samim et al. [12] described three types of bipartite patella according to Saupe et al.'s classification. The first one involves the lower pole of the patella; the second one involves the lateral margin
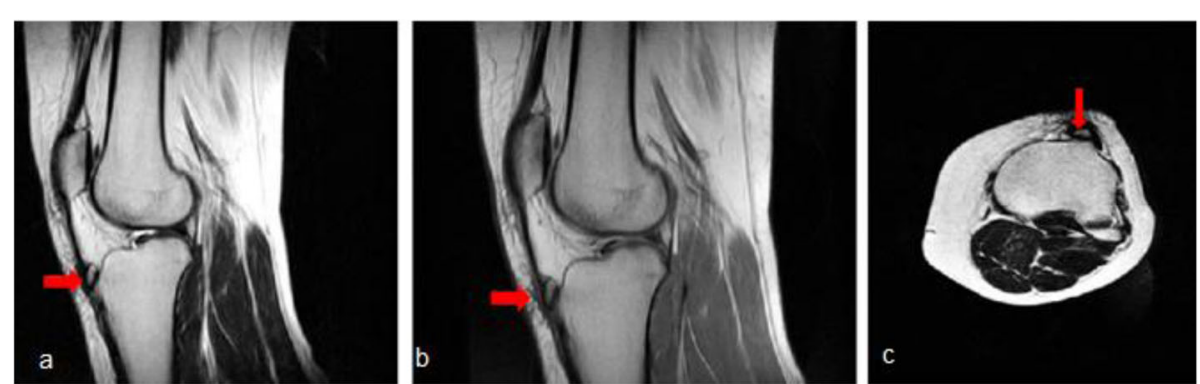

Fig. 13 a-c MRI images for old Osgood-Schlatter disease. a Sagittal T2, b sagittal PD, and c axial T2-weighted images demonstrated fragmentation of the tibial tuberosity (red arrows) with no surrounding soft tissue edema 

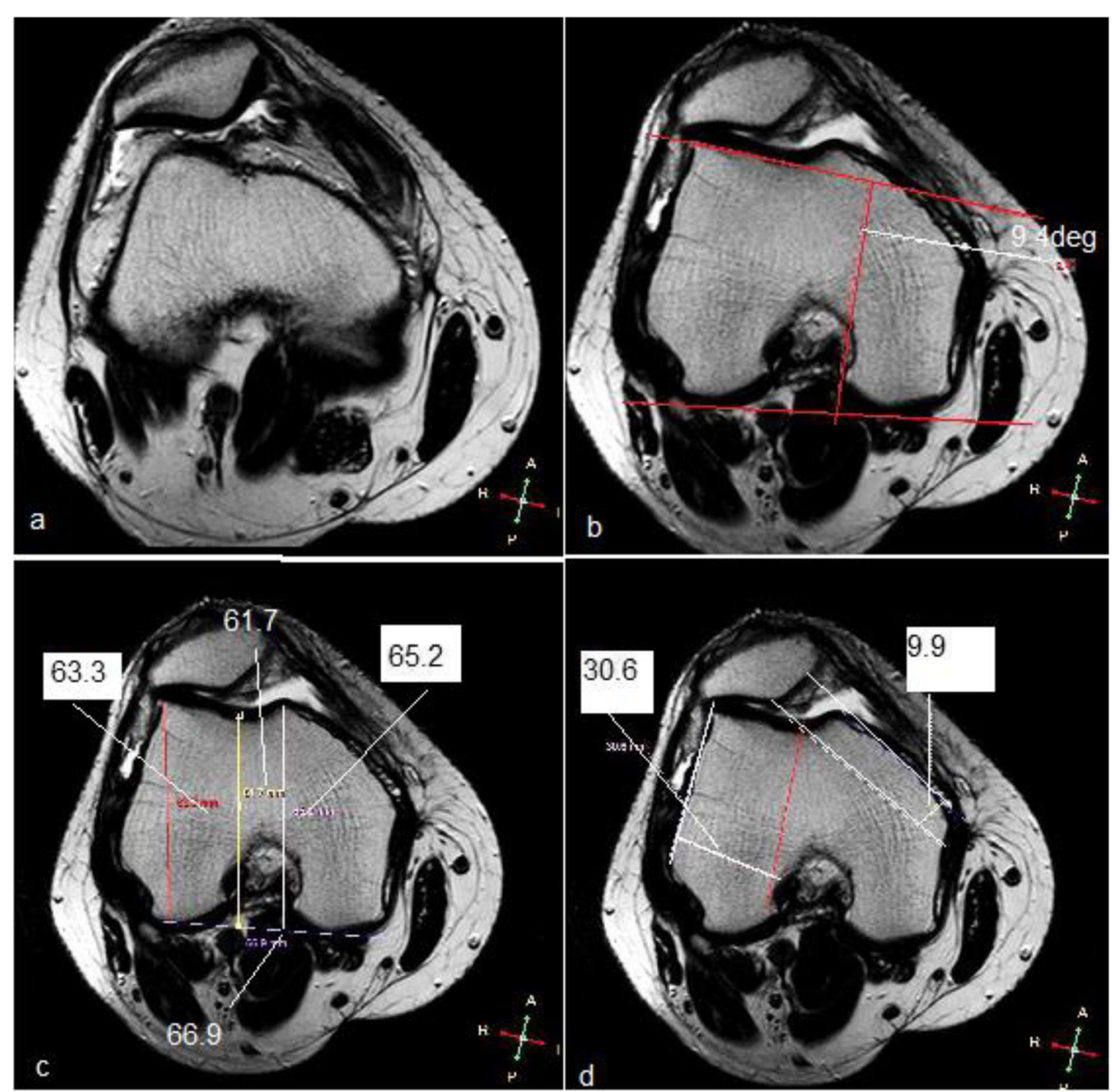

Fig. 14 a-d MRI images for lateral patellar subluxation with trochlear dysplasia type $C$ as a predisposing factor. a Axial T2WI demonstrated loss of contact between the patellofemoral joint surfaces laterally. b Axial T2WI demonstrated a lateral inclination angle about $9.4^{\circ}$. c Axial T2WI demonstrated a trochlear groove depth about $2 \mathrm{~mm}$. d Axial T2WI demonstrated a trochlear facet asymmetry 33\%

of the patella, and the third one-which is considered as the most common type-involves the upperlateral pole.

In a study done by Kavanagh et al. [27], the bone marrow edema that was detected within the bipartite fragment was considered as the sole finding in $49 \%$ of the patients who had a symptomatic bipartite patella. In our study, $3 \%$ of the patients $(2 / 70)$ with AKP had a symptomatic bipartite patella. Both of them were of the third type (at the superolateral patellar pole) and had MRI evidence of bone marrow edema within their bipartite fragments (Fig. 6).

Chung et al.'s [28] study enrolled 50 patients with AKP and reported that $50 \%$ of the sample had Hoffa impingement syndrome with a female predominance. In our study, only $14 \%$ of patients showed edema within the Hoffa pad of fat with respect to female predominance to account for about $70 \%$ of the sample size, and male $30 \%$ (Tables 5, 6, and 8). So, our study is concordant with Chung et al.'s study as regards the gender but differs in the prevalence and this might be explained by the difference in the criteria of the selected sample between the two studies, as Chung et al. excluded patients outside the ages of 14-50 years or those with a history of direct trauma to the knee, while in our study both were included.

Anterior meniscal tear and cartilage injuries were considered by McNally et al. [26], among the main causes of AKP. MRI is considered as the study of choice in cases of the meniscal tear; moreover, it may replace the unnecessary arthroscopy for such entity of disease [10]. In our results, about $13 \%$ of the patients in the study sample had MRI evidence of a tear in the anterior horn of lateral knee meniscus with a female predominance $(67 \%$ females and $33 \%$ males). Their age average was 27 years, $78 \%$ of them had a history of trauma. Only $22 \%$ were above the age of 45 and had no past history of knee trauma (Tables 6 and 8). 

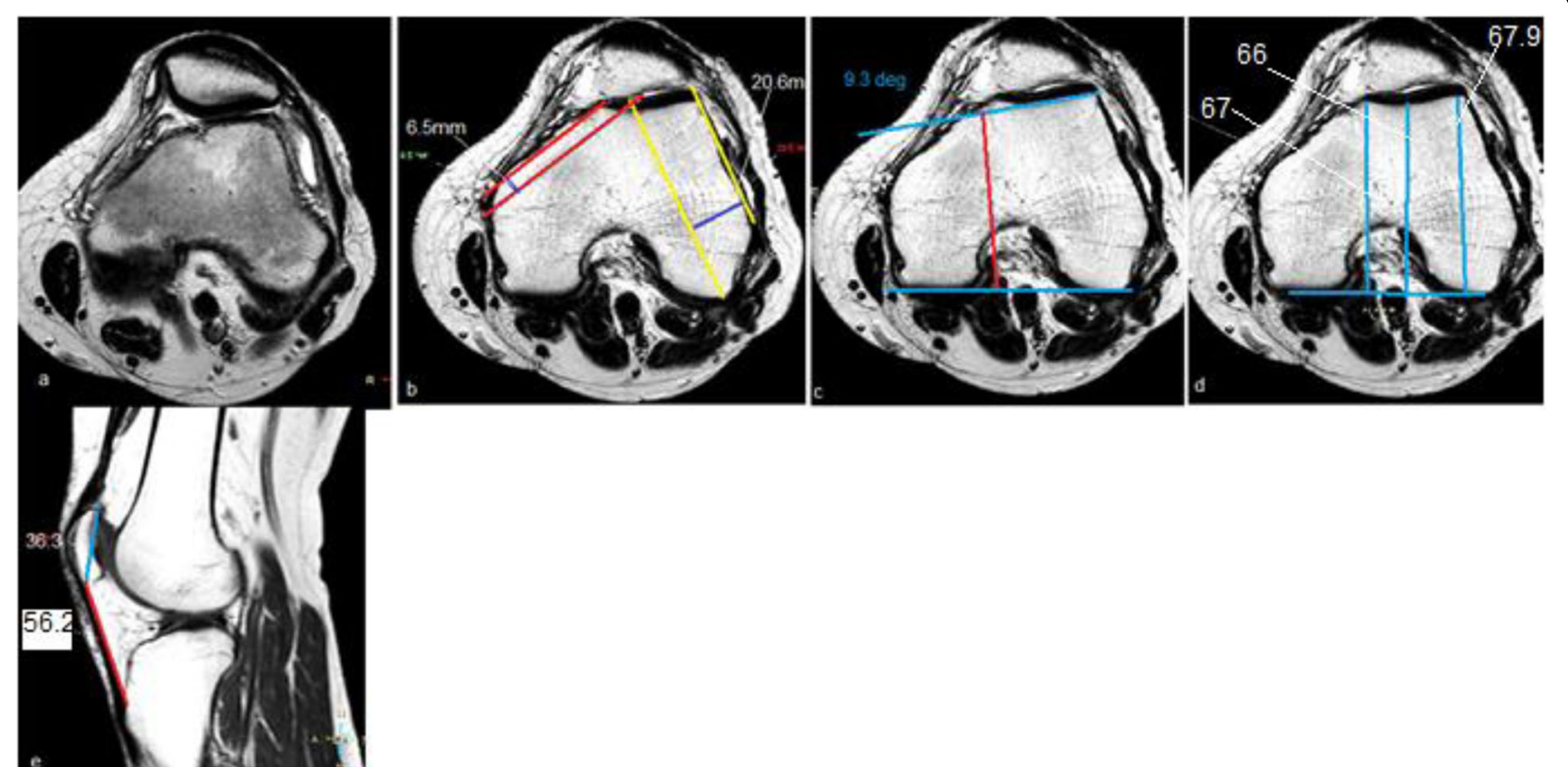

Fig. 15 a-d MRI images for lateral patellar tilt with patella alta and trochlear dysplasia type $C$ as predisposing factors. a Axial T2-weighted image showed loss of contact between the patellofemoral joint surfaces laterally. b Axial T2-weighted image showed trochlear facet asymmetry 32\% (normally not less than 40\%). c Axial T2-weighted image showed lateral inclination angle $9.3^{\circ}$ (normally not less than $11^{\circ}$. d Axial T2-weighted image showed a trochlear depth of $1.5 \mathrm{~mm}$ (normally up to $3 \mathrm{~mm}$ ). e Sagittal PDWI showed patella alta (Insall-Salvati index about 1.5)

The articular cartilage injury may mimic the meniscal tears and might be associated with less satisfactory arthroscopic results; thus, it would be beneficial to have an MRI examination prior to intervention to sort out the patients who might get benefit from cartilage replacement therapies [29].

A variety of articular cartilage injuries had been described as post-traumatic sequelae including fissures, chondral flaps or tears, and loss of a segment of articular cartilage; however, these lesions may be detected as a sole finding or might be associated with other abnormalities.

Table 11 Demonstrating the statistically calculated minimum, maximum, median, and the mean values of the trochlear groove depth by $\mathrm{mm}$, trochlear facet asymmetry by $\%$, and the lateral inclination angle by

\begin{tabular}{|c|c|c|c|c|c|c|c|c|c|}
\hline & \multicolumn{3}{|c|}{$\begin{array}{l}\text { Depth of trochlear } \\
\text { groove by } \mathrm{mm}\end{array}$} & \multicolumn{3}{|c|}{$\begin{array}{l}\text { Trochlear facet } \\
\text { asymmetry by } \%\end{array}$} & \multicolumn{3}{|c|}{$\begin{array}{l}\text { Lateral inclination } \\
\text { angle by }\end{array}$} \\
\hline & $\begin{array}{l}\text { Type } \\
\text { A }\end{array}$ & $\begin{array}{l}\text { Type } \\
\text { B }\end{array}$ & $\begin{array}{l}\text { Type } \\
\text { C }\end{array}$ & & $\begin{array}{l}\text { Type } \\
\text { B }\end{array}$ & $\begin{array}{l}\text { Type } \\
\text { C }\end{array}$ & $\begin{array}{l}\text { Type } \\
\text { A }\end{array}$ & & \\
\hline & 3.00 & 1.500 & 1.500 & 35.00 & 33.00 & 32.00 & 10.00 & 1.500 & 9.300 \\
\hline & 6.00 & 4.000 & & & 60.00 & 50.00 & & & \\
\hline 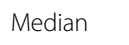 & 5.00 & 2.000 & 2.000 & 3900 & 55.00 & 33.00 & 20.00 & 9.000 & 9.400 \\
\hline & & & 1.035 & & 50.60 & 38.33 & 17.80 & 9.540 & 13.90 \\
\hline D & 1.15 & 1.000 & 0.289 & 6.221 & 10.45 & 10.11 & 5.586 & 8.032 & 7.881 \\
\hline
\end{tabular}

In our results, cartilage injuries were detected in $6 \%$ of the study sample, showing a male predominance $(75 \%$ were male and $25 \%$ were female) with average age 32 years. All had a past history of trauma. It is worth mentioning that $25 \%$ of cartilage injury cases were associated with the anterior meniscal tear (Tables 6 and 8).

\section{Conclusion}

MRI is generally a safe, accurate, and specific modality which has been proven to be the modality of choice in the diagnosis of different knee pathologies that cause AKP in different age groups. Also, it has a high specification for detecting the grades and the types of some of these diseases or factors that may predispose to them such as trochlear dysplasia and patella alta.

Table 12 Demonstrating the percentage of the patellar instability and the transient patellar dislocation

\begin{tabular}{llll}
\hline & & $\begin{array}{l}\text { No. of } \\
\text { patients }\end{array}$ & Percentage \\
\hline $\begin{array}{llll}\text { Patella } \\
\text { dislocation }\end{array}$ & Patellar instability & 13 & $72.22 \%$ \\
& $\begin{array}{l}\text { Transient patellar } \\
\text { dislocation }\end{array}$ & 5 & $27.78 \%$ \\
& Sum & 18 & $100.00 \%$ \\
\hline
\end{tabular}




\section{Abbreviations}

AKP: Anterior knee pain; MRI: Magnetic resonance imaging: PFP: Patellofemoral pain

\section{Acknowledgements}

Not applicable.

\section{Authors' contributions}

The corresponding author ABB had contributed by doing some complementary ultrasound examinations and the interpretation of the MRI images in the research work. He also had a share in the editing of the manuscript and reference collection. KMS had the idea of the research work and revised the editing process. TAH had a role in the image interpretation and the measurements. SGM had the role of patient clinical assessment and in the patient selection. SIS had supervised the MRI examinations and for the workstation measurements. She had shared in the editing process and in the reference collection. All authors read and approved the final manuscript.

\section{Funding}

The authors received no funding for this research and had no competing interests.

\section{Availability of data and materials}

All data are available on a software system owned by each of the authors, and the corresponding author has the authority to respond if there is any query.

\section{Ethics approval and consent to participate}

The protocol was reviewed and approved by the local ethics committee of the radiology department, Kasr Aliny hospital, Cairo University.

The reference number was not applicable.

All patients had given their written consents to participate in this work.

\section{Consent for publication}

All patients had given their written consents for the publication of this work.

\section{Competing interests}

The authors declare that they have no competing interests.

\section{Author details}

'Diagnostic and Interventional Radiology Department, Kasr Aliny Hospital, Cairo University, Cairo, Egypt. ${ }^{2}$ Orthopedic Surgery, Faculty of Medicine, Cairo University, Cairo, Egypt.

Received: 27 November 2019 Accepted: 2 December 2019

Published online: 30 December 2019

\section{References}

1. Collado H, Fredericson M (2010) Patellofemoral pain syndrome. Clin Sports Med 29:379-398

2. Witvrouw E et al (2000) Intrinsic risk factors for the development of anterior knee pain in an athletic population. A two-year prospective study. Am J Sports Med 28:480-489

3. Biedert RM, Sanchis-Alfonso V (2002) Sources of anterior knee pain. Clin Sports Med 21:335-347 Vii

4. Escala JS et al (2006) Objective patellar instability: MR-based quantitative assessment of potentially associated anatomical features. Knee Surg Sports Traumatol Arthrosc 14(3):264-272

5. Recht MP et al (1996) Accuracy of fat-suppressed three-dimensional spoiled gradient-echo FLASH MR imaging in the detection of patellofemoral articular cartilage abnormalities. Radiology 198:209-212

6. Insall J, Goldberg V, Salvati E (1972) Recurrent dislocation and the highridings patella. Clin Orthop Relat Res 88:67-69

7. Diederichs G, Issever AS, Scheffler S (2010) MR imaging of patellar instability: injury patterns and assessment of risk factors. Radiographics 30:961-981

8. Carrillon Y et al (2000) Patellar instability: assessment on MR images by measuring the lateral trochlear inclination-initial experience. Radiology 216:582-585

9. Pfirrmann CW et al (2000) Femoral trochlear dysplasia: MR findings. Radiology 216(3):858-864

10. Mcnally et al (2000) Assessment of patellar maltracking using combined static and dynamic MRI. Eur Radiol 10:1051-1055
11. Benjamin $\mathrm{M}$ et al (2006) Where tendons and ligaments meet bone: attachment sites ( entheses') in relation to exercise and/or mechanical load. J Anat 208:471-490

12. Samim M et al (2014) MRI of anterior knee pain. Skeletal Radiol. https://doi. org/10.1007/500256-014-1816-7

13. Gottsegen CJ et al (2008) Avulsion fractures of the knee: imaging findings and clinical significance. Radiographics 28:1755-1770

14. Niitsu M (2013) Magnetic resonance imaging of the knee. Springer-Verlag, Berlin

15. Aparicio G et al (1997) Radiologic study of patellar height in OsgoodSchlatter disease. J Pediatr Orthop 17:63-66

16. Pocock CA, Trikha SP, Bell JS (2008) Delayed reconstruction of a quadriceps tendon. Clin Orthop Relat Res 466:221-224

17. Pfirrmann CW et al (2008) Quadriceps tendinosis and patellar tendinosis in professional beach volleyball players: sonographic findings in correlation with clinical symptoms. Eur Radiol 18:1703-1709

18. Grelsamer RP (2005) Patellar nomenclature: the tower of babel revisited. Clin Orthop Relat Res 436:60-65

19. Chang G, Horng A, Glaser C (2011) A practical guide to imaging of cartilage repair with emphasis on bone marrow changes. Semin Musculoskelet Radiol 15:221-237

20. Mattila VM et al (2012) Sensitivity of MRI for articular cartilage lesions of the patellae. Scand J Surg SJS 101:56-61

21. Toms AP et al (2009) Imaging the femoral sulcus with ultrasound, CT, and MRI: reliability and generalizability in patients with patellar instability. Skelet Radiol 38(4):329-338

22. Kirsch MD et al (1993) Transient lateral patellar dislocation: diagnosis with MR imaging. AJR Am J Roentgenol 161:109-113

23. Dejour D, Le Coultre B (2007) Osteotomies in patello-femoral instabilities. Sports Med Arthrosc 15:39-46

24. Nelitz M et al (2012) Analysis of failed surgery for patellar instability in children with open growth plates. Knee Surg Sports Traumatol Arthrosc 20:822-828

25. Fithian DC et al (2004) Epidemiology and natural history of acute patellar dislocation. Am J Sports Med 32:1114-1121

26. McNally G (2001) Imaging assessment of anterior knee pain and patellar maltracking. Skelet Radiol 30:484-495

27. Kavanagh EC et al (2007) MRI findings in bipartite patella. Skelet Radiol 36:209-214

28. Chung CB et al (2001) Patellar tendon-lateral femoral condyle friction syndrome: MR imaging in 42 patients. Skelet Radiol 30:694-697

29. McCauley TR, Disler DG (2001) Magnetic resonance imaging of articular cartilage of the knee. J Am Acad Orthop Surg 9:28

\section{Publisher's Note}

Springer Nature remains neutral with regard to jurisdictional claims in published maps and institutional affiliations.

\section{Submit your manuscript to a SpringerOpen ${ }^{\circ}$ journal and benefit from:}

- Convenient online submission

- Rigorous peer review

- Open access: articles freely available online

High visibility within the field

- Retaining the copyright to your article

Submit your next manuscript at $>$ springeropen.com 